\title{
Simulating the dynamics of occupant behaviour for thermal comfort in social housing
}

\author{
Jeetika Malik ${ }^{1}$, Ronita Bardhan ${ }^{1,2}$, Pradipta Banerji ${ }^{1}$ \\ ${ }^{1}$ Indian Institute of Technology Bombay, Mumbai 400076, India. \\ ${ }^{2}$ University of Cambridge, Cambridge, CB3 9DT, UK.
}

\begin{abstract}
The way occupants adapt in an environmental setting directly affects their perceived thermal comfort. This study examines the variation in thermal comfort perception due to the diversified occupant behaviour. The self-reported occupant behaviour patterns within the social housing were clustered into three groups based on the newly developed index, Adaptive Behaviour Index. A dynamic building simulation approach was then employed to investigate the difference in thermal comfort using "Annual Comfort Hours" as the quantifying metric. The results revealed that Annual Comfort Hours for "active" and "passive" occupants were $247 \%$ and $180 \%$ higher than that of the "indifferent" occupants respectively. This study recognises the role of multifaceted occupant behaviour in developing better models of adaptive thermal comfort.
\end{abstract}

\section{Introduction}

Thermal comfort is one of the critical functions that people are concerned about in the buildings. It is defined as "the condition of mind in which satisfaction is expressed with thermal environment" and is assessed by subjective evaluation (ASHRAE, 2017). The adaptive approach to thermal comfort identifies occupant behaviour (OB) as a key factor in establishing thermal comfort. The existing adaptive thermal comfort standards such as ISO 7730 (ISO, 2005) and ASHRAE Standard-55 (ASHRAE, 2017) are based on the notion that the occupants' level of adaptation is strongly related to outdoor climatic conditions. However, occupants' adaptive behaviour is also influenced by socio-cultural, economic and contextual factors (Yan and Hong, 2018). This oversimplification of $\mathrm{OB}$ often results in an incorrect judgement of thermal comfort ranges leading to a difference in actual energy consumption than predicted. Thus, an in-depth understanding of $\mathrm{OB}$ is of utmost importance to improve indoor occupant comfort and reduce building energy use.

Occupant behaviour (OB) refers to the interaction with building systems to control the indoor environment for health and to obtain thermal, visual and acoustic comfort inside buildings (Delzendeh, Wu, Lee and Zhou, 2017). Such behaviour could be categorized into adaptive and non-adaptive actions (Hong, Yan, D'Oca and Chen, 2017). Adaptive actions for thermal comfort include either changing the environment to adapt according to occupant's need such as opening or closing of windows, adjusting thermostats, using heaters/space coolers etc. or adapting themselves to the environment by adjusting clothing, drinking hot/cold beverages etc. The nonadaptive actions include reporting discomfort, occupant presence or no action. The way occupants adapt in an environmental setting directly affects their perceived thermal comfort. A deeper understanding about the nature and factors influencing $\mathrm{OB}$ within buildings is therefore critical in providing indoor comfort. Though a lot of researchers have discussed the importance of $\mathrm{OB}$ in thermal comfort, the magnitude of such influence is still unknown (Indraganti and Rao, 2010; Kim, De Dear, Parkinson and Candido, 2017; Rijal, Humphreys and Nicol, 2009).

This work aims at investigating the variability of thermal comfort due to different occupant behaviour (OB) patterns, particularly for the case of social housing. The study focusses on the stochastic and diverse nature of $\mathrm{OB}$ which often leads to a difference in perceived comfort within the same residential setting. The multi-storeyed residential buildings with multi-tenant rooms on each floor, commonly known as chawls, located in Mumbai, India are chosen as the study area. These densely packed tenement blocks are often characterized as thermally uncomfortable with poor indoor environment due to lack of ventilation and daylight (Bardhan, Debnath, Malik and Sarkar, 2018; Bardhan, Sarkar, Jana and Velaga, 2015). Furthermore, the adaptive actions for achieving thermal comfort in these dwellings are governed by socio-cultural and economic practices, i.e. the social logic (Malik and Bardhan, 2018). This study analyses the impact OB patterns, constrained by the social logic, on indoor thermal comfort. The main objectives of this study are:

- To understand the role of occupant behaviour in improving thermal comfort within social housing.

- To identify the diversity in adaptive behaviour patterns adopted by the occupants using statistical methods.

- To assess the variation in thermal comfort due to the adaptive occupant behaviour through a data-driven simulation approach.

The novelty of this study is twofold. Firstly, this study explores thermal comfort behaviour in the oftenneglected category of social housing. Secondly, this study adopts a relatively newer method involving a combination of statistical analysis and simulation techniques to quantify the effect of occupant behaviour (OB) on thermal 
comfort. This work relies on the self-reported $\mathrm{OB}$ in social housing while accounting for the social logic.

\section{Research Methods}

A mixed mode research design involving transverse survey, statistical analysis and building simulation modelling approach has been adopted in this study. A questionnaire survey was conducted to apprehend the adaptive occupant behaviour (OB) for thermal comfort improvements. The responses from the survey were collated and statistically examined using multivariate analysis techniques to cluster the OB patterns into three distinct groups. Each OB cluster was treated as a case and translated as an input for simulating the case study building. Thermal comfort assessments were then made from the simulation results to identify the variation in the representative cases.

\section{Data Collection}

A cross-sectional questionnaire survey method was adopted to capture the occupant behaviour $(\mathrm{OB})$ patterns in social housing of Mumbai, India. This method is useful because of its ability to account for the social logic and the rationale behind the behaviour patterns which the sensor-based monitoring is not capable of (Day, Theodorson and Arch, 2012). The survey was designed based on the thermal comfort and OB studies conducted in residential buildings by Indraganti (2011) (Indraganti, 2011), Andersen et. al (2009) (Andersen, Toftum, Kaae and Olesen, 2009) and Rajasekar and Ramachandraiah, (2010) (Rajasekar and Ramachandraiah, 2010). Questions were structured to elicit responses regarding demography, household characteristics, adaptive actions for thermal comfort, door and window opening schedules, ownership of space-conditioning appliances and their usage, satisfaction with indoor thermal environment. The respondents were also enquired about the reasons and the potential constraints for adopting such behaviour. The survey did not include questions on comfort perception and was limited to occupant behaviour towards thermal comfort.

A pilot study was conducted on 33 respondents in two social housing colonies to test the measurement instrument. The survey form was revised accordingly to improve the reliability and minimise response bias. In addition, single blinding method was adopted to avoid Hawthorne effect and improve the quality of data. Questionnaire surveys were carried out by seven welltrained interviewers in five different locations across Mumbai between February and June 2018. The respondents were interviewed in person using the computer-aided personal interview (CAPI) method. CAPI method is advantageous over traditional paper-based survey method as it yields better quality results, has a higher response rate and is less time-consuming. Random stratification of the samples was done based on age, location of house, and condition of house. 1267 respondents, each representing a distinct household, participated in the survey. 1223 valid response forms were yielded since 44 of the respondents refused to complete the process. The survey responses were then statistically analysed to test the validity and reliability of the data. Table 1 explains the distribution of responses regarding age, education, household income and household size.

Table 1: Socio-economic characteristics of samples.

\begin{tabular}{cc}
\hline Variable & $\begin{array}{c}\text { Average (Standard } \\
\text { Deviation) }\end{array}$ \\
\hline Age (in years) & $37.97(11.95)$ \\
Household Size & $4.68(1.65)$ \\
\hline Variable & Percentage \\
\hline Household Income (INR) & 8.9 \\
Below 5000 & 54.5 \\
5000-10000 & 34.3 \\
10000-25000 & 2.2 \\
25000-50000 & 0.1 \\
Above 50000 & \\
Education & 30.0 \\
Below Primary school & 30.2 \\
Primary school & 20.7 \\
Secondary school & 9.1 \\
Higher secondary school & 10.0 \\
Graduation and above & \\
\hline
\end{tabular}

\section{Constructing Occupant Behaviour Index}

This section explains the analysis of survey responses using the statistical package, SPSS v24. The aim was to identify the diversity of occupant behaviour (OB) within the dataset. This was done through the development of an index, termed as Adaptive Behaviour Index (ABI) for categorising $\mathrm{OB}$ into distinct groups. $\mathrm{ABI}$ index was dependent on the level of adaptive actions taken by the occupants to modify their indoor environment. The variables chosen for computing ABI were extracted from the survey responses based on their potential to improve indoor thermal comfort. Use of environmental controls such as ceiling fans, exhaust, air-conditioners etc., adjustment of indoor environment through adaptation measures and level of dependency on cooling equipment were observed as the influencing factors for improving thermal comfort. Socio-demographic aspects were not considered since it was not possible to translate these variables into building simulation model.

Table 2 gives the descriptive statistics of the five variables chosen for computing ABI. A detailed description of each of these variables is given below:

1. Adaptive strategies (AS): This variable comprised of passive strategies for achieving comfort adopted by the occupants. Most commonly adopted strategies were the use of curtains for shading, use of planters near the window sill and clothing adjustments. A few households also adopted roof wetting to improve thermal comfort; however, this strategy was not very efficient in the humid climate.

2. Natural ventilation controls (NV): In naturally ventilated buildings, air velocity is a crucial factor for thermal comfort improvements since it is not possible to modify indoor air temperature and humidity. Thus, most of the households relied on window and door opening to achieve thermal comfort. The second variable, $\mathrm{NV}$, consisted of door and window opening controls which were the most common adaptive 
action taken by the occupants. However, the responses revealed that these controls were not accessed at times due to security, privacy, spaceconstraints and other contextual constraints.

3. Cooling equipment usage (CU): This variable accounted for the ownership and usage of ceiling fans, evaporative coolers and air-conditioners. 99\% of the households adopted the usage of ceiling fans and the operating hours varied from 12 to 24 hours a day depending upon the occupancy, occupant preference and outdoor weather conditions. $5.7 \%$ of the surveyed households had air-conditioners for space cooling which refutes the general notion that social housing is associated with low-income and are not energy intensive. However, the usage of these energy-intensive devices was intermittent and restricted to 2-10 hours a day due to high operating costs. Evaporative coolers and room heaters were not common in these households with a combined ownership of less than $0.1 \%$.

4. Mechanical Ventilation controls (MV): The fourth variable, MV, explained the ownership and usage of other space-conditioning equipment such as exhaust fans and dehumidifiers. About $13 \%$ of the respondents used exhaust fans, especially while cooking.

5. Cooling months $(\mathrm{CM})$ : This variable indicated the number of months each household relied on cooling equipment for thermal comfort improvement. It captured the intensity of usage of the cooling equipment. The survey revealed that the ceiling fans were used for almost 9-12 months a year whereas air conditioners were used for 3-8 months a year.

Table 2: Descriptive statistics of variables used for computing Adaptive Behaviour Index.

\begin{tabular}{|c|c|c|c|c|c|}
\hline Variable & Description & Min & Max & Mean & S.D. \\
\hline $\mathrm{AS}$ & $\begin{array}{l}\text { Number of } \\
\text { adaptive } \\
\text { strategies } \\
\text { adopted }\end{array}$ & 0 & 4 & 1.35 & 1.11 \\
\hline NV & $\begin{array}{c}\text { Use of } \\
\text { natural } \\
\text { ventilation } \\
\text { controls }\end{array}$ & 0 & 3 & 1.92 & 1.99 \\
\hline MV & $\begin{array}{l}\text { Use of } \\
\text { exhaust fans }\end{array}$ & 0 & 1 & 0.55 & 0.50 \\
\hline $\mathrm{CM}$ & $\begin{array}{l}\text { Number of } \\
\text { months } \\
\text { relying on } \\
\text { cooling }\end{array}$ & 6 & 12 & 10.33 & 1.37 \\
\hline $\mathrm{CU}$ & $\begin{array}{l}\text { Intensity of } \\
\text { cooling } \\
\text { equipment } \\
\text { usage }\end{array}$ & 0 & 12 & 4.08 & 1.33 \\
\hline
\end{tabular}

Occupant behaviour is influenced by multiple factors such as physical, contextual, social, physiological (IEA, 2018; Yan et al., 2015) and cannot be measured using a single direct variable. Therefore, Principal Component Analysis
(PCA), a statistical dimension reduction technique, was performed for aggregation of data into a single Adaptive Behaviour Index (ABI) with little loss of information. This method has been widely applied in fields such as urban planning, real estate and healthcare to develop composite indices from multivariate data. (Bardhan, Kurisu and Hanaki, 2015; Baroni, Barthélémy and Mokrane, 2007; Sathyakumar, Ramsankaran and Bardhan, 2019) In PCA, the dimensionality of multivariate data is reduced by transforming the correlated variables into a set of uncorrelated linear combination of variables, called as principal components (PC). PCs account for much of the variance among the set of original variables with the first $\mathrm{PC}$ accounting for the maximum possible variation. This approach of utilising the first PC for regression coefficients was adopted in this study. The statistical analysis was carried out in IBM SPSS v25 Software using the standard factor analysis procedure. The procedure involves standardisation of variables by calculating $\mathrm{z}$-scores followed by the computation of factor loadings also called as weights. The $\mathrm{z}$-scores are then multiplied by the loadings and summed to produce the ABI value for each household as explained in equation (1). The resultant $\mathrm{ABI}$ scores were standardised having a mean of zero and a standard deviation of one.

$$
\begin{gathered}
A B I_{i}=F_{1} \times Z_{X 1}+F_{2} \times Z_{X 2}+\cdots \\
+F_{n} \times Z_{X n}
\end{gathered}
$$

where,

$\mathrm{ABI}_{\mathrm{i}}=$ Adaptive Behaviour Index score

$\mathrm{F}_{\mathrm{n}}=$ factor loading assigned to the $\mathrm{nth}$ variable

$\mathrm{Z}_{\mathrm{Xn}}=\mathrm{Z}$-score of the $\mathrm{nth}$ variable

$\mathrm{n}=$ no. of variables.

The next step was to classify the diverse OB patterns based on their ABI scores such that demonstrated behaviours with similar thermal comfort consequences are grouped together. For example, occupants using higher level of adaptation or those relying on energyintensive cooling equipment would fall within the same cluster. Clustering is one of the most widely used pattern recognition methods and aims at partitioning the dataset into a set of unsupervised groups or clusters (Diao, Sun, Chen and Chen, 2017). Cluster analysis was carried out using a combination of hierarchical and k-means clustering methods for arriving at better results. Hierarchical cluster analysis was adopted to identify the rough number of clusters based on within cluster inertia gains since this method provides the freedom to choose the number of clusters based on dendrogram structure (Huang, Lu and Sellers, 2007). K-means cluster analysis, a commonly adopted technique for clustering $\mathrm{OB}$ patterns, was then employed to make the classification (D'Oca and Hong, 2014; Dong, Li and McFadden, 2015). Typical occupant behaviour patterns were identified corresponding to each cluster and translated as input for simulating different cases as explained in the subsequent section. 


\section{Simulation Approach}

\section{Study Area}

An existing building located in one of the social housing colonies of Mumbai, India was chosen as the case study. The building block consisted of 84 single room units, commonly called chawls, spread across four floors along a double-loaded corridor (see Figure 1). Each tenement unit had an area of around 19.5 square meters with a clear height of 2.9 meters. An integrated cooking space was provided inside each unit with an LPG cookstove. The fenestrations included a door opening into the common corridor and an external operable window. The tenement units majorly relied on fan-assisted natural ventilation. However, mixed mode ventilation methods were also adopted in a few tenement units.

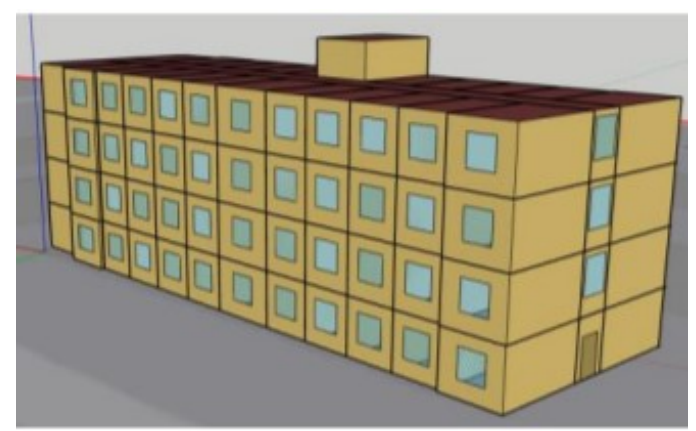

Figure 1: Rendering of the simulation model.

\section{Model Description}

Energyplusv8.6 was used to perform the building performance analysis because of its capability to simulate a building close to its real situation. Openstudiov2.5, a cross-platform tool for modelling and analysis of building systems, was employed to model the study building. The weather data file for Mumbai city was imported from the nearest weather station located in Santacruz, $14 \mathrm{kms}$ away from case study building. Mumbai is characterised by warm and humid climate with a mean annual temperature of $27.2^{\circ} \mathrm{C}$. The construction materials were modelled as per the existing specifications to construct an as-built model. Testo 653-2 thermohygrometer set was used for in-situ measurements of the U-values of building envelope materials. Table 3 provides the building material properties and other simulation input parameters used for simulation. Each chawl unit was treated as an individual zone having a household size of five with different weekday and weekend occupancy schedules based on the survey results. All the 84 zones, i.e. chawl units were simulated for an annual period to obtain hourly Predicted Mean Vote (PMV). PMV is an index that predicts the votes of large groups of persons on a 7-point thermal sensation scale ranging from +3 (hot) to -3 (cold) where 0 indicates thermal neutrality (International Organization for Standardization, 2005). The PMV values obtained from simulated results were based on Fanger's comfort equation and dependent on six variables namely: air temperature, relative humidity, relative air velocity, mean radiant temperature, metabolic rate and clothing insulation.
Table 3: Simulation Input parameters.

\begin{tabular}{|c|c|c|c|c|}
\hline Parameter & Material & $\begin{array}{l}\text { Thickness } \\
\text { (in mm) }\end{array}$ & $\begin{array}{c}\text { U-Value } \\
\text { (W/m²- } \\
\text { K) }\end{array}$ & Source \\
\hline Walls & Brick & 200 & 1.8 & $\begin{array}{l}\text { As per } \\
\text { actual }\end{array}$ \\
\hline Roof & Concrete & 150 & 3.6 & CARBSE \\
\hline Floor & Concrete & 150 & 3.6 & (2019) \\
\hline Infiltration & \multicolumn{4}{|c|}{ Through minor cracks } \\
\hline Occupancy & \multicolumn{3}{|c|}{$\begin{array}{l}\text { Separate weekday and weekend } \\
\text { occupancy schedule }\end{array}$} & Refer \\
\hline Lighting & \multicolumn{3}{|c|}{$\begin{array}{l}\text { T8 fluorescent light operational for } \\
16 \text { hours a day }\end{array}$} & $\begin{array}{l}\text { Appendix. } \\
\text { A }\end{array}$ \\
\hline Cooking & \multicolumn{4}{|c|}{$\begin{array}{l}\text { One LPG cookstove operational for } \\
3.5 \text { hours a day }\end{array}$} \\
\hline Equipment & \multicolumn{4}{|c|}{$\begin{array}{l}\text { Television, Washing machine and Refrigerator } \\
\text { (one each) }\end{array}$} \\
\hline $\begin{array}{l}\text { Ventilation } \\
\text { system }\end{array}$ & \multicolumn{3}{|c|}{ As per different OB patterns } & $\begin{array}{c}\text { Refer } \\
\text { Appendix } \\
\text { B }\end{array}$ \\
\hline
\end{tabular}

An advantage of applying PMV approach over the adaptive approach for non-air-conditioned buildings is that it includes all the major variables influencing thermal sensation and doesn't rely only on the average monthly outdoor temperature (Fanger and Toftum, 2002a). However, Fanger model underestimates the PMV for naturally ventilated and mixed-mode buildings, and an adjustment was required to account for this inadequacy (Yao, Li and Liu, 2009). A correction factor of 0.7, based on field studies in hot and humid climate (Fanger and Toftum, 2002b; Zhang, Wang, Chen, Zhang, and Meng, 2010) was considered to calculate Zone hourly adjusted PMV values, as per equation (2).

$$
\begin{gathered}
\text { Adjusted Zone Hourly PMV Value }=0.7 * \text { Zone } \\
\text { Hourly PMV Value }
\end{gathered}
$$

The identified patterns corresponding to each cluster were treated as different cases, and annual simulations were performed to obtain hourly adjusted PMV values. The simulated results were then compared based on the thermal comfort assessment criteria as discussed in the next section.

\section{Thermal comfort assessment criteria}

Thermal comfort assessments for different cases were carried out using "Annual Comfort Hours" as a quantifying metric. Adjusted PMV values falling within the acceptable range, i.e. +0.5 to -0.5 , following the thermal environment classification of ISO7730 (see Table 4) were considered as comfortable. The rest of the hours were treated as discomfort hours. "Annual comfort hours" were calculated for the entire year as the sum of total comfort hours out of 8760 hours.

Table 4: Thermal environment classification: ISO 7730.

\begin{tabular}{cccc}
\hline Category & PPD & PMV Range & Description \\
\hline A & $<6 \%$ & -0.2 to +0.2 & Good \\
B & $<10 \%$ & -0.5 to +0.5 & Acceptable \\
C & $<15 \%$ & -0.7 to +0.7 & Compromised \\
\hline
\end{tabular}




\section{Results}

\section{Adaptive Behaviour Index (ABI)}

The dataset was statistically analysed to check for reliability using the criteria of Cronbach's alpha $(\alpha)$. The $\alpha$ value of 0.63 , which was within the acceptable range, established the internal consistency reliability of the data. The correlation between the variables ranged from 0.074 to 0.789 . The next step involved checking the adequacy of the data for performing Principal Component Analysis (PCA) using Kaiser-Meyer-Olkin (KMO) and Bartlett's Test of Sphericity. The adequacy check yielded an acceptable KMO value of 0.584 (Cerny and Kaiser, 1977) which was found to be statistically significant ( $p$ value $=0.00$ ) as mentioned in Table 5. Thus, the variables were suited for performing PCA.

Table 5: KMO and Bartlett's test results.

\begin{tabular}{ccc}
\hline \multicolumn{2}{c}{ Criteria } & Resultant Values \\
\hline \multicolumn{2}{c}{ Kaiser-Meyer-Olkin (Measure of } & 0.584 \\
Sampling Adequacy) & 1477.533 \\
& Approx. Chi-Square & 10 \\
$\begin{array}{c}\text { Bartlett's Test } \\
\text { of Sphericity }\end{array}$ & df & 0.000
\end{tabular}

The first principal component (PC1) from PCA results explained the maximum possible variability and was considered to measure occupant behaviour (OB). ABI which is a weighted aggregation of five variables was used to quantify OB. The ABI score was computed as a comprehensive value of the five variables obtained from regression equation using $\mathrm{PC} 1$. The resultant equation (Equation 3) having an intercept of zero could be expressed as:

$$
\begin{array}{r}
\mathrm{ABI}=-0.592 \mathrm{AS}-0.887 \mathrm{NV}+0.853 \mathrm{MV} \\
+0.368 \mathrm{CU}+0.319 \mathrm{CM}
\end{array}
$$

Table 6 indicates the weights of five ABI variables derived from PCA results. These regression coefficients indicate a positive relation of ABI with Adaptive Strategies (-0.592) and Natural Ventilation Control (0.887 ) and negative relationship with Mechanical Ventilation (0.853), Cooling Equipment Usage (0.368) and Cooling Months (0.319). It could be inferred that ABI principally explains the $\mathrm{OB}$ concerning energy use for improving thermal comfort. A higher $\mathrm{ABI}$ would indicate energy-intensive $\mathrm{OB}$ patterns while a lower $\mathrm{ABI}$ value would suggest that occupants are engaged in either lowenergy adaptive actions or non-adaptive actions.

Table 6: Weights (Factor loadings) of ABI variables

\begin{tabular}{ccc}
\hline Variable & Factor score & Relation \\
\hline AS & -0.592 & Negative \\
NV & -0.887 & Negative \\
MV & 0.853 & Positive \\
CU & 0.368 & Positive \\
CM & 0.319 & Positive \\
\hline
\end{tabular}

\section{Occupant Behaviour Classification}

The occupant classification based on the ABI scores resulted in three clusters. Figure 2 illustrates the ABI ranges for each cluster and their median values. The height of each box plot in Figure 2, depicts the cluster range, which was a measure of intracluster diversity in occupant behaviour. The ABI scores ranged from 1.04 to 8.51 with Cluster 2 having the maximum deviation and Cluster 1 having the minimum deviation. The ABI score for Cluster 1 ranged from 1.04 to 2.27 with a median value of 1.63. Cluster 2 had the widest ABI range from 2.32 to 6.44 indicating diversity in $\mathrm{OB}$ within the cluster. The median value of Cluster 2 was 4.24 . Cluster 3 had a moderate deviation with a score range of 6.52 to 8.51 .

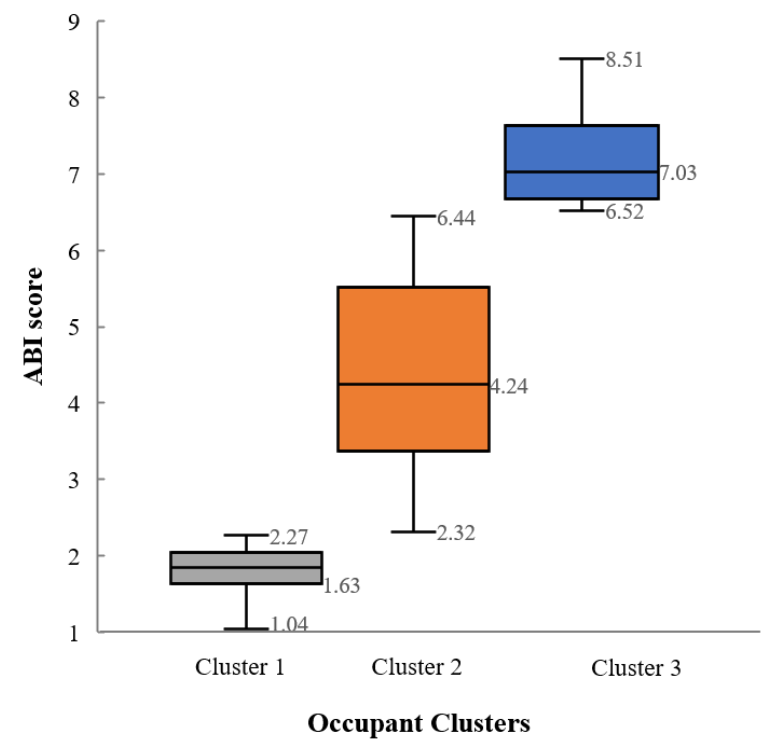

Figure 2: Classification of $O B$ based on the ABI scores.

Typical occupant behaviour patterns were then extracted for each cluster from the survey responses (see Table 7). The nomenclature of clusters was done based on the characteristics of OB patterns. The lowest value cluster, Cluster 1 was termed as "passive" since the occupants adopted passive measures for achieving thermal comfort such as the use of NV controls, curtains or adapting themselves through adjusting clothing levels. This behaviour could be attributed to the energy-consciousness of the occupants or the existence of fuel poverty. Cluster 2 was called as "indifferent" because the occupants within this cluster did not engage much in adaptive actions and were indifferent to thermal comfort improvements. They majorly relied on the use of ceiling fans and window opening for increased air velocity. Lack of awareness and/or socio-cultural and economic constraints were the major drivers for such behaviour. Cluster 3, termed as "active", belonged to the occupants with dependency on active measures such as the use of air-conditioners and exhaust fan. A narrow thermal tolerance band and relatively lesser economic constraints were the main reasons for such behaviour. 
Table 7: Occupant behaviour patterns based on clustering.

\begin{tabular}{|c|c|c|c|c|}
\hline Parameter & $\begin{array}{l}\text { Cluster } 1 \\
\text { Passive } \\
\end{array}$ & $\begin{array}{c}\text { Cluster } 2 \\
\text { Indifferent }\end{array}$ & $\begin{array}{l}\text { Cluster } 3 \\
\text { Active } \\
\end{array}$ & Details \\
\hline Opening of doors & Yes & No & No & \multirow{3}{*}{$\begin{array}{c}\text { Detalls } \\
\text { Open when the inside temperature exceeds the } \\
\text { temperature setpoint of } 26^{\circ} \mathrm{C} \text { (Hwang, Cheng, Lin, \& } \\
\text { Ho, 2009; Kubota et al., 2018) or the outdoor air } \\
\text { temperature. } \\
\text { Drawn if high solar gain }(<0.7) \text { incident on windows }\end{array}$} \\
\hline Opening of windows & Yes & Yes & $\begin{array}{l}\text { Yes, if } \\
\text { HVAC off }\end{array}$ & \\
\hline Use of Curtains & Yes & No & No & \\
\hline Use of Planters & Yes & No & No & \multirow{2}{*}{$\begin{array}{l}\text { Plant assembly having a conductivity of } 18 \mathrm{~W} / \mathrm{m}-\mathrm{K} \\
\text { Based on season, ranging from } 0.57 \text { to } 0.96 \text { clo }\end{array}$} \\
\hline $\begin{array}{l}\text { Clothing level } \\
\text { adjustment }\end{array}$ & Yes & No & No & \\
\hline Ceiling fan use (daily) & 12-18 hours & 12 hours & 18-24 hours & \multirow[b]{2}{*}{$\begin{array}{l}\text { Operational as per schedule (Appendix B) resulting in } \\
\text { the room air velocity of } 0.7 \mathrm{~m} / \mathrm{s}\end{array}$} \\
\hline $\begin{array}{l}\text { Average Months of } \\
\text { operation }\end{array}$ & 9.21 & 10.48 & 11.8 & \\
\hline Exhaust Fan use & Yes & No & Yes & \multirow{2}{*}{ Operated while cooking with a max. flow of $601 / \mathrm{s}$} \\
\hline Months of operation & 12 & 0 & 10 & \\
\hline Air-conditioner & No & No & Yes & \multirow[b]{2}{*}{$\begin{array}{l}\text { 1-ton unit operational for 2-6 hours during March- } \\
\text { Nov as per schedule (Appendix B) }\end{array}$} \\
\hline Months of operation & 0 & 0 & 9.5 & \\
\hline
\end{tabular}

\section{Thermal Comfort Assessment}

Building simulations were carried out for the three cases as identified in the previous section. The simulation results revealed that the occupants of the subject dwellings experienced thermally uncomfortable environment for a significant amount of year under all the three cases. Figure 3 illustrates the duration curves of acceptable adjusted PMV (aPMV) values for each case as the percentage of the year. It was observed that "active" occupants had the acceptable aPMV values for the largest time of the year as compared to the other two cases. Yet, for over $60 \%$ of the year, the aPMV values were outside the acceptable comfort ranges. The aPMV curves revealed that most of the thermal discomfort for "active" and "passive" occupants was attributed to slightly warm or warm conditions since the aPMV values ranged between 0.5 to 1.5 for a larger part of the year. The "indifferent" behaviour curve witnessed aPMV value lying within the acceptable range for only a small part of the year (14\%). Furthermore, these values were farthest from the acceptable range for a large part of the year indicating extreme discomfort.

Annual comfort hours were calculated for these cases to investigate the variability of thermal comfort. The results revealed that the "active" occupants were found to be the most thermally comfortable with an annual comfort hour value of 3010 while the "indifferent" occupants experienced the least thermal comfort with 1217 comfortable hours in a year. Figure 4 depicts the annual and seasonal variation in thermal comfort across the cases. Annual comfort hours for the "active" and "passive" occupants were found to be $247 \%$ and $180 \%$ higher than that of the "indifferent" occupants respectively. The monsoon season (June to September) observed the highest seasonal variation of annual comfort hours. "Active" occupants were more thermally comfortable in monsoons since the passive measures often fail to provide thermal neutrality in high humidity conditions. The summer (March to May) and postmonsoon season (October and November) also witnessed similar trends where "active" occupants had the highest comfort hours. The seasonal variation in winter months (December to February) witnessed an interesting trend with the "passive" occupants having a higher comfort level in comparison to the "active" occupants. The reason was that the active occupants did not use the airconditioners in winter months and were engaged in nonadaptive actions.

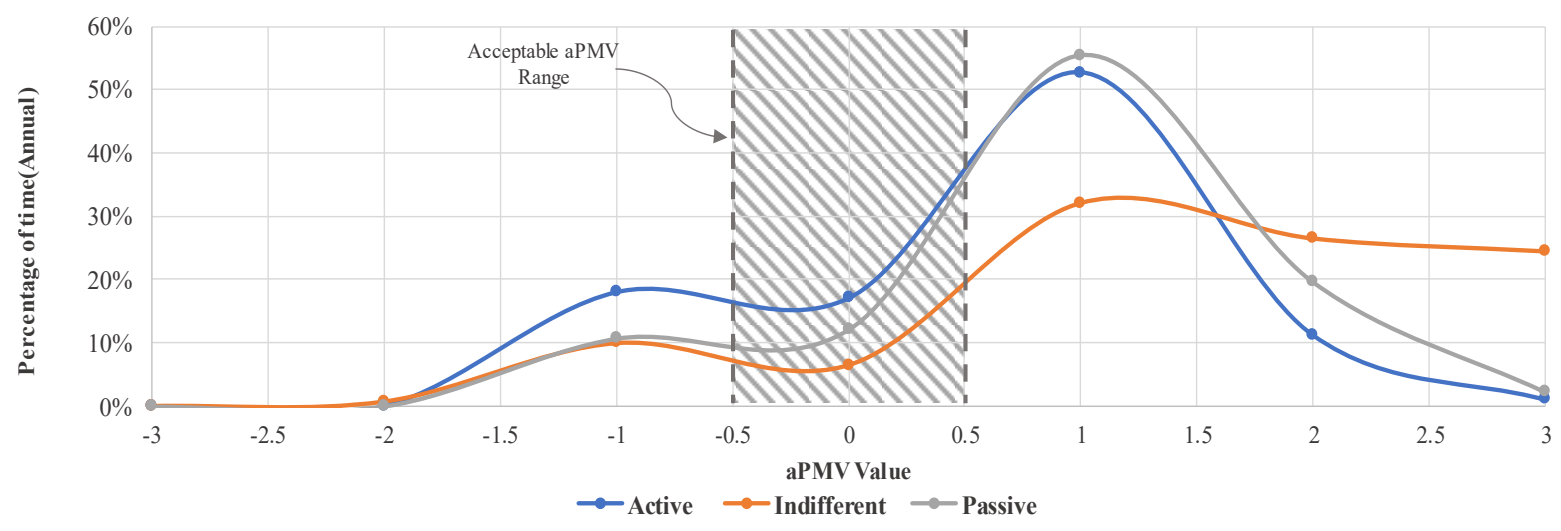

Figure 3: Duration curves for aPMV values for three cases. 


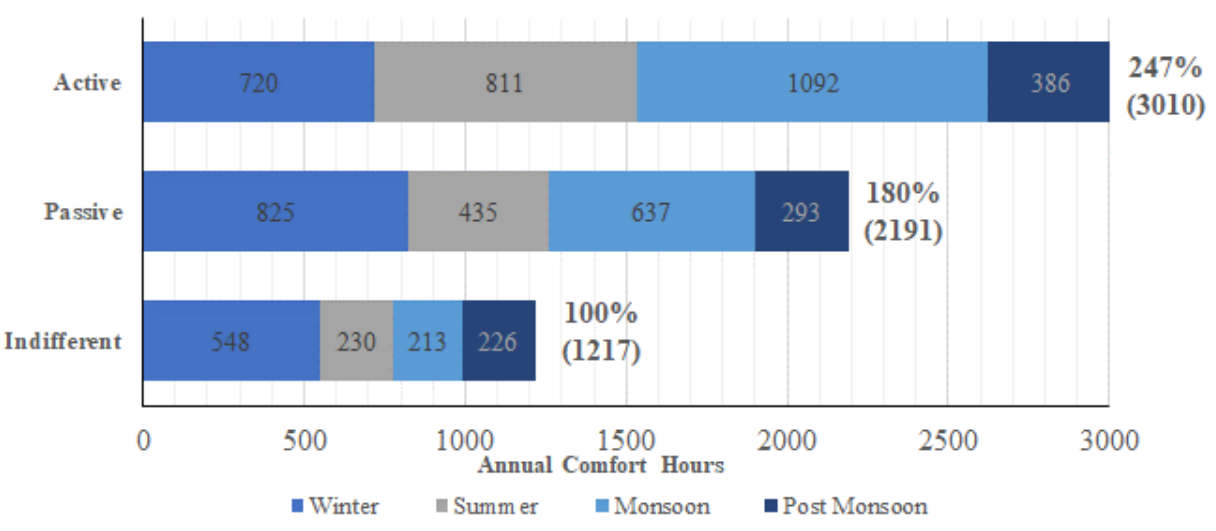

Figure 4: Annual and seasonal variation of annual comfort hours.

\section{Limitations}

As to the limitations, the OB patterns considered here are majorly deterministic and do not account much for the stochasticity. A probabilistic approach using sophisticated OB modelling and co-simulation tools could help in a better translation and integration of the $\mathrm{OB}$ patterns thereby improving the accuracy of results. Another limitation of this study lies in its thermal comfort assessment approach based on Fanger's model. Though an adjustment factor for non-air-conditioned building has been incorporated, the model is still not suitable for Indian social housing context where the external factors (e.g. economic and contextual) may alter occupant's thermal acceptance and neutrality. The effect of these factors on thermal assessment was sidestepped in this study, possibly because no obvious approach was available. However, an effort was made to deal with this shortcoming by analysing the results on a relative scale rather than an absolute one.

\section{Conclusion}

This work aimed at establishing the role of occupant behaviour in thermal comfort domain through a datadriven simulation approach. The self-reported occupant behaviour patterns in the social housing of Mumbai were incorporated in the dynamic simulation models for investigating the variability of thermal comfort. The OB patterns, which are often influenced by the social logic, were categorized into- "active", "passive" and "indifferent" clusters based on the Adaptive Behaviour Index (ABI). Annual comfort hours was used a metric for quantification and comparison of thermal comfort among the different OB clusters. The results demonstrated a stark variation, as high as $147 \%$, in annual comfort hours within the same residential setting indicating a significant role of OB in thermal comfort improvement. The study also highlighted the rationale behind adopting the reported occupant behaviour which comprised of socio-cultural, contextual and economic constraints. This study paves the way for incorporating the stochastic and diverse OB to develop better models of adaptive thermal comfort.

\section{Acknowledgements}

Part of this study is funded by the Ministry of Human Resource Development (MHRD), the Government of India (GoI) project titled CoE-FAST, Grant No. 14MHRD005 and IRCC- IIT Bombay Fund, Grant No. 16IRCC561015. Any opinions, findings, and conclusions or recommendations expressed in this material are those of the authors and do not necessarily reflect the views of the MHRD, GoI and/or IRCC-IIT Bombay.

\section{References}

Andersen, R. V., Toftum, J., Andersen, K. K. and Olesen, B. W. (2009). Survey of occupant behaviour and control of indoor environment in Danish dwellings. Energy and Buildings 41, 11-16.

Bardhan, R., Debnath, R., Malik, J. and Sarkar, A. (2018). Low-income housing layouts under socioarchitectural complexities: A parametric study for sustainable slum rehabilitation. Sustainable Cities and Society 41, 126-138.

Bardhan, R., Kurisu, K. and Hanaki, K. (2015). Does compact urban forms relate to good quality of life in high density cities of India? Case of Kolkata. Cities 48, 55-65.

Bardhan, R., Sarkar, S., Jana, A. and Velaga, N. R. (2015). Mumbai slums since independence: Evaluating the policy outcomes. Habitat International 50, 1-11.

Baroni, M., Barthélémy, F. and Mokrane, M. (2007). A PCA Factor Repeat Sales Index for Apartment Prices in Paris. Journal of Real Estate Research 29(2), 137-158.

Cerny, B. A. and Kaiser, H. F. (1977). A Study Of A Measure Of Sampling Adequacy For FactorAnalytic Correlation Matrices. Multivariate Behavioral Research 12(1), 43-47.

D’Oca, S. and Hong, T. (2014). A data-mining approach to discover patterns of window opening and closing behavior in offices. Building and Environment 82, 726-739.

Day, J., Theodorson, J. and Arch, M. (2012). Understanding Controls, Behaviors and 
Satisfaction in the Daylit Perimeter Office: A Daylight Design Case Study, Journal of Interior Design 37(1), 17-34.

Delzendeh, E., Wu, S., Lee, A. and Zhou, Y. (2017). The impact of occupants' behaviours on building energy analysis: A research review. Renewable and Sustainable Energy Reviews 80(August), 10611071.

Diao, L., Sun, Y., Chen, Z. and Chen, J. (2017). Modeling energy consumption in residential buildings: A bottom-up analysis based on occupant behavior pattern clustering and stochastic simulation. Energy and Buildings 147, 47-66.

Dong, B., Li, Z. and McFadden, G. (2015). An investigation on energy-related occupancy behavior for low-income residential buildings. Science and Technology for the Built Environment 21(6), 892901.

Fanger, P. O. and Toftum, J. (2002a). Extension of the PMV model to non-air-conditioned buildings in warm climates. Energy and Buildings 34(6), 533536.

Fanger, P. O. and Toftum, J. (2002b). Prediction of thermal sensation in non-air conditioned buildings in warm climates. Proceedings from $9^{\text {th }}$ International Conference on Indoor Air Quality and Climate. Monterey (CA), 30 June-5 July 2002.

Hong, T., Yan, D., D’Oca, S. and Chen, C. (2017). Ten questions concerning occupant behavior in buildings: The big picture. Building and Environment 114, 518-530.

Huang, J., Lu, X. X. and Sellers, J. M. (2007). A global comparative analysis of urban form: Applying spatial metrics and remote sensing. Landscape and Urban Planning 82(4), 184-197.

Hwang, R. L., Cheng, M. J., Lin, T. P. and Ho, M. C. (2009). Thermal perceptions, general adaptation methods and occupant's idea about the trade-off between thermal comfort and energy saving in hothumid regions. Building and Environment 44(6), 1128-1134.

Yan, D. and Hong T. (2018). Definition and Simulation of Occupant Behavior in Buildings: Annex 66 Final Report. International Energy Agency, EBC Annex 66

Indraganti, M. (2011). Thermal comfort in apartments in India: Adaptive use of environmental controls and hindrances. Renewable Energy 36(4), 1182-1189.

Indraganti, M. and Rao, K. D. (2010). Effect of age, gender, economic group and tenure on thermal comfort: A field study in residential buildings in hot and dry climate with seasonal variations. Energy and Buildings 42(3), 273-281.

International Organization for Standardization (2005).
Ergonomics of the thermal environment Analytical determination and interpretation of thermal comfort using calculation of the PMV and PPD indices and local thermal comfort criteria. (ISO 7730).

Kim, J., de Dear, R., Parkinson, T. and Candido, C. (2017). Understanding patterns of adaptive comfort behaviour in the Sydney mixed-mode residential context. Energy and Buildings 141, 274-283.

Lalloué, B., Monnez, J., Padilla, C., Kihal, W., Meur, N. Le, Zmirou-navier, D. and Deguen, S. (2013). A statistical procedure to create a neighborhood socioeconomic index for health inequalities analysis. International Journal for Equity in Health 12(21), 1-11.

Malik, J. and Bardhan, R. (2018). Optimizing Thermal Comfort in Low-Income Dwellings: A Pinch Analysis Approach. Proceedings of the 4th IBPSAEngland Conference on Building Simulation and Optimization. Cambridge (UK), 11-12 September 2018.

Rajasekar, E. and Ramachandraiah, A. (2010). Adaptive comfort and thermal expectations-a subjective evaluation in hot humid climate. Proceedings from Adapting to Change: New Thinking on Comfort, Windsor Conference. Windsor (UK), 9-11 April 2010.

Rijal, H. B., Humphreys, M. A. and Nicol, J. F. (2009). Understanding occupant behaviour: The use of controls in mixed-mode office buildings. Building Research and Information, 37(4), 381-396.

Sathyakumar, V., Ramsankaran, R. and Bardhan, R. (2019). Linking remotely sensed Urban Green Space (UGS) distribution patterns and SocioEconomic Status (SES) - A multi-scale probabilistic analysis based in Mumbai, India. GIScience \& Remote Sensing 56, 645-669.

ASHRAE (2017). ASHRAE/ANSI Standard 55-2017 Thermal environmental conditions for human occupancy.

Yan, D., O’Brien, W., Hong, T., Feng, X., Burak Gunay, H., Tahmasebi, F. and Mahdavi, A. (2015). Occupant behavior modeling for building performance simulation: Current state and future challenges. Energy and Buildings 107, 264-278.

Yao, R., Li, B. and Liu, J. (2009). A theoretical adaptive model of thermal comfort - Adaptive Predicted Mean Vote (aPMV). Building and Environment 44(10), 2089-2096.

Zhang, Y., Wang, J., Chen, H., Zhang, J. and Meng, Q. (2010). Thermal comfort in naturally ventilated buildings in hot-humid area of China. Building and Environment 45(11), 2562-2570. 
Appendix A: Standard Occupancy, Lighting and Cooking Schedule

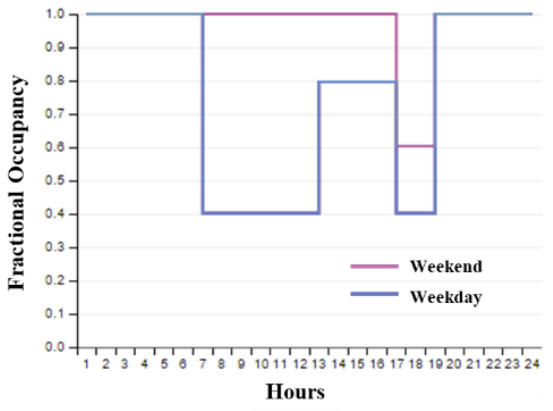

Occupancy Schedule

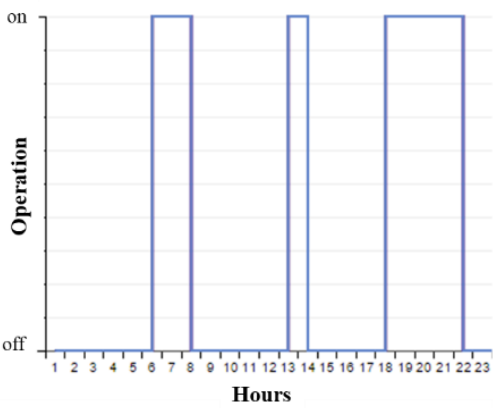

Lighting Schedule

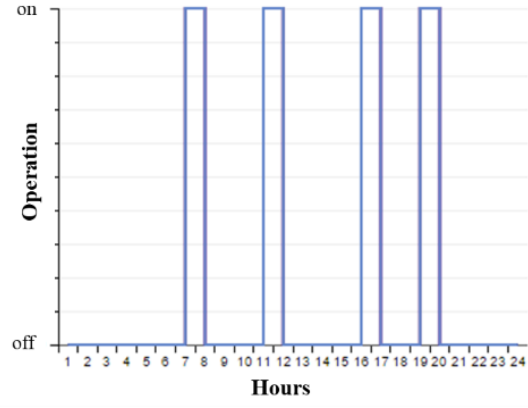

Cooking Schedule

Appendix B: Ventilation and Air-conditioning Schedules
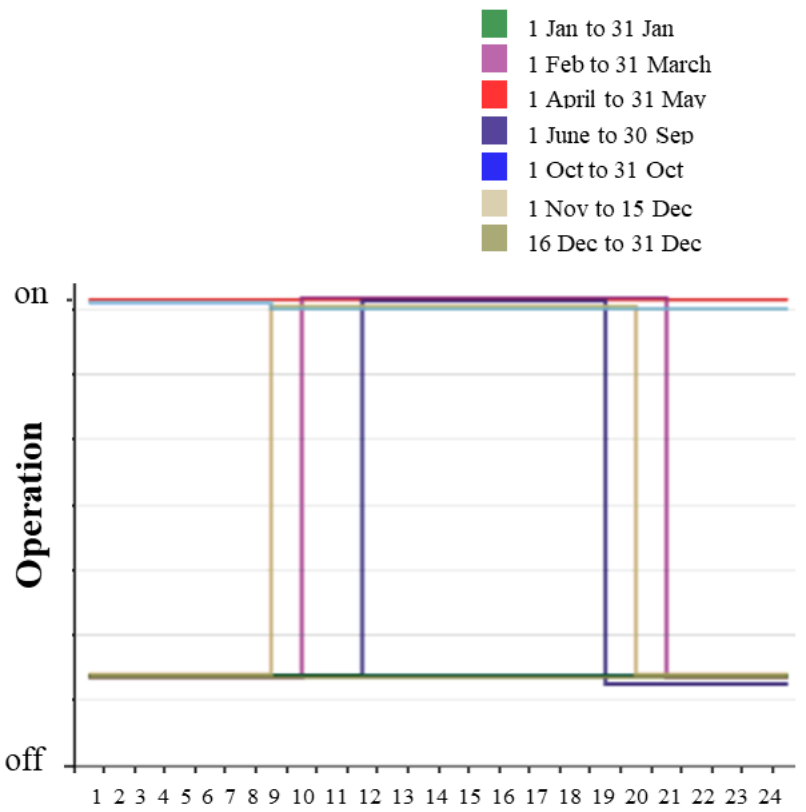

Hours

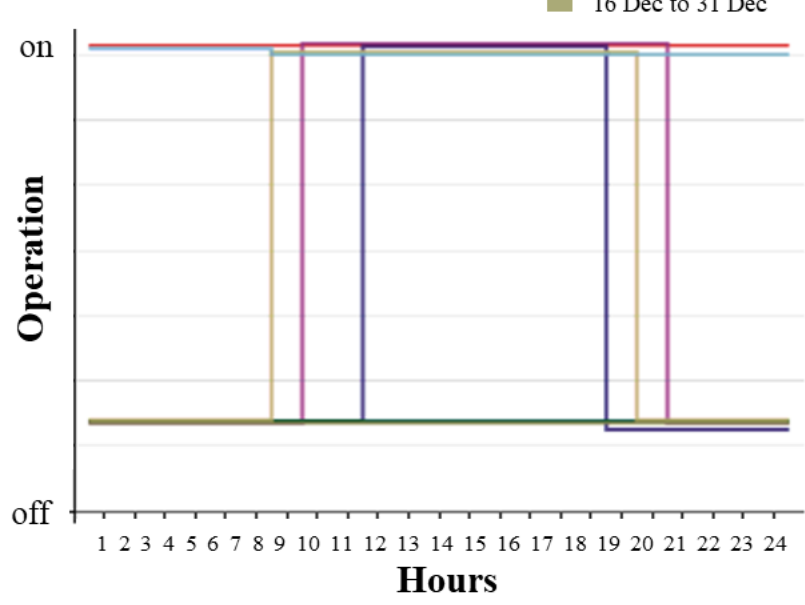

Ceiling Fan Schedule: Cluster 2
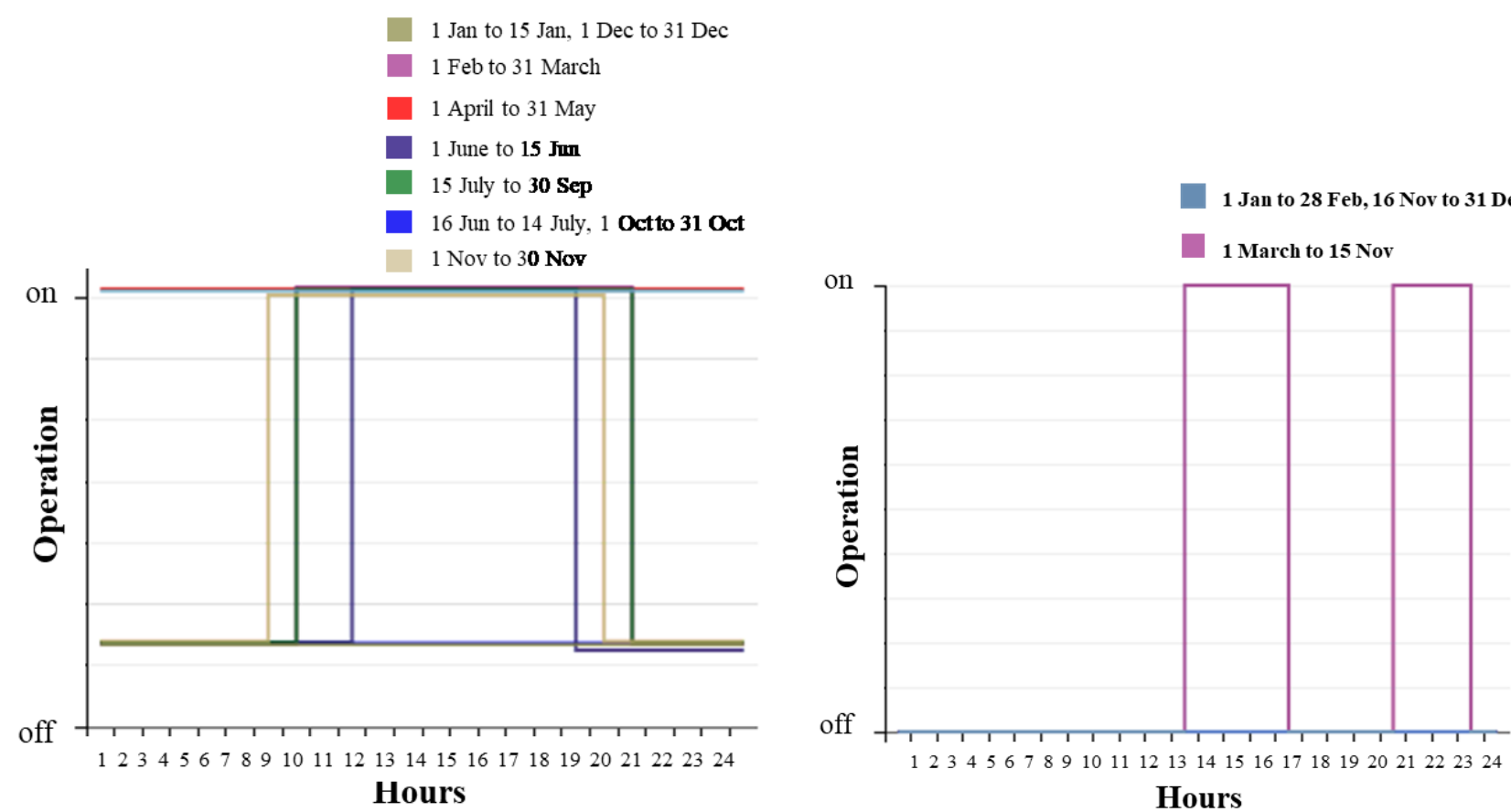

Hours 